\title{
Relationship between Damping Factor and Compressive Residual Stress for Shot-Peened Austenitic Stainless Steel
}

\author{
Lakhwinder Singh, ${ }^{1}$ R. A. Khan, ${ }^{2}$ and M. L. Aggarwal ${ }^{1}$ \\ ${ }^{1}$ Department of Mechanical Engineering, YMCA University of Science \& Tech., Faridabad 121006, India \\ ${ }^{2}$ Department of Mechanical Engineering, Jamia Millia Islamia, New Delhi 110025, India
}

Correspondence should be addressed to Lakhwinder Singh, lakhwinder_ymca@hotmail.com

Received 29 January 2011; Accepted 8 March 2011

Academic Editors: J.-L. Marcelin and A. Tounsi

Copyright ( $) 2011$ Lakhwinder Singh et al. This is an open access article distributed under the Creative Commons Attribution License, which permits unrestricted use, distribution, and reproduction in any medium, provided the original work is properly cited.

The mechanical properties of austenitic stainless steel are rarely improved by heat treatment. Shot peening is a well-known cold working process that affects thin surface of materials. By controlling the shot peening intensity and shot size, the variable mechanical properties film thickness was obtained from $0.05 \mathrm{~mm}$ to $0.5 \mathrm{~mm}$. The damping factor and compressive residual stress are determined experimentally and forming a relation between them. It was found that damping factor in thin film surface increases with depth of deformed layer. An investigation was carried out, and it was found that the increase in damping factor was due to introduction of compressive residual stress and increased hardness due to shot peening. The paper discusses a model of changing damping properties with compressive residual stress and depth of deformed layer of austenitic stainless steel.

\section{Introduction}

The method of heat treatment in stainless steel depends on the type of stainless steel and the reason for the treatment. Heat treatment processes such as annealing, hardening, stress relieving, and so forth restore desirable properties such as corrosion resistance, hardness, toughness, ductility, and damping. These heat treatments processes are done prior to the fabrication operation to produce hard structure which is able to withstand high stresses or abrasion in service.

Stainless Steel is a highly corrosion resistant material due to the presence of $\mathrm{Cr}$ along with the other alloying elements like nickel and molybdenum. From the classification on the basis of the predominant phase constituent of the microstructure, the austenitic stainless steel is most corrosion resistant. This makes its wide application in chemical and food processing equipments, medical equipments, cryogenic vessels, and so forth. Hence, it is better to have hardenability, fatigue strength, damping, and tensile strength, along with the corrosion resistant in various applications.

Mechanical systems under cyclic loading normally present structural vibrations. These vibrations can cause noise and fatigue problems. Materials which are able to absorb the mechanical energy related to vibrations are called damping materials. Talonen and Hänninen have investigated the damping capacity of two cold rolled stainless steel grades EN 1.4318 and EN 1.4301 [1].

Cold working is used to increase strength, especially in highly alloyed austenitic stainless steels [2]. The improvement in mechanical properties such as hardness, fatigue strength, tensile strength, and damping are due to the induction of compressive residual stress in the metal parts. Shot peening is a well-known cold working process that affects thin surface of materials. The shot peening variables like shot material, shot quality, shot intensity, shot coverage, and so forth affect the mechanical properties. The impact produced by the shots is sufficient to create plastic deformation of the surface up to certain depth which results in the induction of compressive residual stress along with the tensile stress at the interior.

The residual compressive stress induced by shot peening on the thin surface of the material is the function of material and mechanical conditions. The magnitude of the compressive stress induced and the depth of the induced layer depend considerably on the peening intensity [3]. Peening intensity can be defined as a measure of the kinetic 


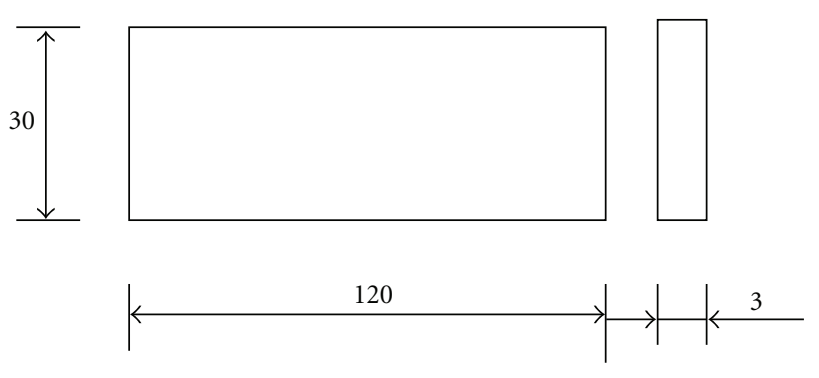

FIgURE 1: Specimen size (all dimensions in $\mathrm{mm}$ ).

TABLE 1: Chemical composition of 304 stainless steel.

\begin{tabular}{cccccccc}
\hline Steel & $\mathrm{C}$ & $\mathrm{Si}$ & $\mathrm{Mn}$ & $\mathrm{P}$ & $\mathrm{S}$ & $\mathrm{Ni}$ & $\mathrm{Cr}$ \\
\hline 304 & 0.08 & 0.75 & 3.0 & 0.042 & 0.03 & 10 & 18 \\
\hline
\end{tabular}

energy within a stream of peening media. Peening intensity attained can vary with shot size, shot hardness, shot speed, shot flow rate, impact angle, coverage, and so forth.

Different materials have different patterns of residual stress for same shot peening condition. Small spherical shots are bombarded in shot peening. Each shot strikes the metal surface and imparts the stress in the form of compression [46]. The induction of compressive residual stress is limited to a very small depth from the surface. Shot peening produces residual compressive stress.

The damping capacity in a system is characterized by a ratio called damping ratio or damping factor. It is the ratio of the logarithmic decrement of any underdamped harmonic motion to its period. It also refers to the amount of damping in an oscillatory system. It is the ratio of damping to critical damping. Damping factor is an important surface characteristic, which varies with shot peening conditions and depth from the surface of materials $[7,8]$. Damping ratio or damping factor of Shot-peened sample is measured by using an experimental setup consisting of a CRO (cathode ray oscilloscope), accelerometer and amplifier. The damping factor is calculated from the logarithmic decrement $(\delta)[9$, $10]$.

In the literature, most of the work done till date on the effect of shot peening on fatigue does not consider the effect of internal damping at various depths of deformed layer and shot peening conditions [11-13]. The induction of compressive residual stress and increased hardness helps in improving the damping factor of the specimen at various shot peening conditions. Damping consideration will lead to prediction of compressive residual stress field easily and economically. The major objective of the present work is to investigate the effects of shot peening for achieving the variable damping and fatigue life in components.

\section{Experimental Details}

The chemical composition of the specimen material (304 austenitic stainless steel) is shown in Table 1 . The mechanical properties of the specimen material are: ultimate tensile strength of $658 \mathrm{MPa}$ and average hardness of $265 \mathrm{VHN}$. The dimensions of specimen for the determination of damping factor are shown in Figure 1.

The shot peening was done by using centrifugal wheel. The cast steel balls of $1 \mathrm{~mm}$ diameter were used to shot peen the specimens. An Almen strip of size $76 \mathrm{~mm} \times 19 \mathrm{~mm} \times$ $1.3 \mathrm{~mm}$ thick was used to measure the intensity of shot peening. The specimens were Shot-peened at different intensity on Almen gauge. In order to measure damping factor at different depths, the layer of specimen was removed, before and after the shot peening operation by electrochemical machining with a nonacidic electrolyte. The coverage of shot peening was $90 \%$.

Damping factor of various specimens was measured by using an experimental setup consisting of a CRO, accelerometer, and amplifier. The specimen was fixed in a jaw, accelerometer was placed on it and then load was applied. The observations in Tables 2 and 3 depict the average of three readings.

The compressive residual stress induced by shot peening was measured by X-ray diffraction method. A Cr tube operated at $30 \mathrm{KV}$, and $8 \mathrm{~mA}$ was used for projecting $\mathrm{K} \alpha 1$ $\mathrm{X}$-rays. The diffraction angle $2 \theta$ without strain was taken as $135.4^{\circ}$.

Fatigue testing was carried out in axial loading fatigue testing system at room temperature. To draw S-N curve, the specimen was used to fail at different stress levels. Stress ratio $(R)$ equal to 0.1 was used during fatigue testing. The dimensions of specimens for ploating $\mathrm{S}-\mathrm{N}$ curve are shown in Figure 2. The dimensions of the specimens were according to the ASTM standards. The different stress levels used for plotting the S-N curve were $265 \mathrm{Mpa}, 240 \mathrm{Mpa}, 225 \mathrm{Mpa}$, and $210 \mathrm{Mpa}$.

\section{Results and Discussion}

3.1. Hardness. The average value of hardness for base material is $265 \mathrm{VHN}$. It was seen that after shot peening the hardness of the specimen increases (Figure 3 ). The effect of shot peening was limited to a very small depth of deformed layer. The hardness increases with the increase in depth of deformed layer. The average hardness after shot peening was $366 \mathrm{VHN}$, and standard deviation was 24 (Table 2). The variation in hardness was found because of the plastic deformation on the metal surface [14].

3.2. Damping Factor. Damping factor is critical property of the material to control the vibrations. Table 3 shows the damping factor of untreated sample. A high value of damping factor limits the amplitude of vibration. Readings for amplitude were measured from the set up shown in Figure 4 in terms of volts. The logarithmic decrement $(\delta)$ was determined by using $(1)[9,10]$

$$
\delta=\frac{1}{N}\left[\ln \left(\frac{X_{1}}{X_{n}}\right)\right],
$$

where $N$ is number of cycles, $X_{1}$ is amplitude of vibration for first cycle, and $X_{n}=$ amplitude of vibration for $N$ th cycle. 
TABLE 2: Variation of hardness and depth of deformed layer for Shot-peened specimens.

\begin{tabular}{lccc}
\hline S. no. & Shot peening intensity (Almen A scale) & Hardness $(\mathrm{VHN})$ & Depth of deformed layer $(\mathrm{mm})$ \\
\hline 1 & $1 \mathrm{~A}$ & 332 & 0.23 \\
2 & $3 \mathrm{~A}$ & 358 & 0.35 \\
3 & $4.5 \mathrm{~A}$ & 380 & 0.44 \\
4 & $6 \mathrm{~A}$ & 396 & 0.50 \\
- & - & Av 366 & - \\
- & - & SD 24 & - \\
\hline
\end{tabular}

TABLE 3: Damping factor for untreated specimen.

\begin{tabular}{lcc}
\hline S. no. & $\begin{array}{c}\text { Thickness of layer } \\
\text { removed from } \\
\text { surface }(\mathrm{mm})\end{array}$ & $\begin{array}{c}\text { Damping factor of } \\
\text { untreated specimen }\end{array}$ \\
\hline 1 & Nil & 0.08936 \\
2 & 0.03 & 0.07689 \\
3 & 0.06 & 0.06239 \\
4 & 0.12 & 0.06013 \\
& Average & 0.07219 \\
\hline
\end{tabular}

So damping factor $(\xi)$ was calculated from the following equation $[9,10]$ :

$$
\delta=\frac{2 \Pi \xi}{\left(1-\xi^{2}\right)^{1 / 2}} .
$$

It was found that damping factor decreases with depth of layer removed from the surface of the specimen. Also damping factor improves with shot peening of 304 austenitic stainless steel (Table 4). It was seen that on the surface damping factor was the same for different shot peening conditions. On subsequent removal of surface layer damping factor varies with different shot peening conditions (Figure 5).

It was also found that with change in shot peening intensity the depth of deformed layer and damping factor changes (Table 4), this is due to induction of compressive stress on the thin layer from the surface. A linear relationship was observed between damping factor depth of deformed layer. The damping factor points were slightly scattered, but a straight line was best fit at different depths of deformed layer for various shot peening condition and depth of layer removed from the surface (Figure 6). Regression analysis was used to fit the straight line in damping and depth of deformed layer data at different shot peening conditions. The expression for damping factor at different shot peening condition is expressed as

$$
\xi=m(D)+C,
$$

where $D$ is depth of deformed layer, $m$ is the slope of the line, and $C$ is the intercept. It is analyse from the data that coefficient of determination $\left(R^{2}\right)$ varies from 0.82 to 0.99 . This value of coefficient of determination indicates the variation of damping factor depends on depth of deformed layer.

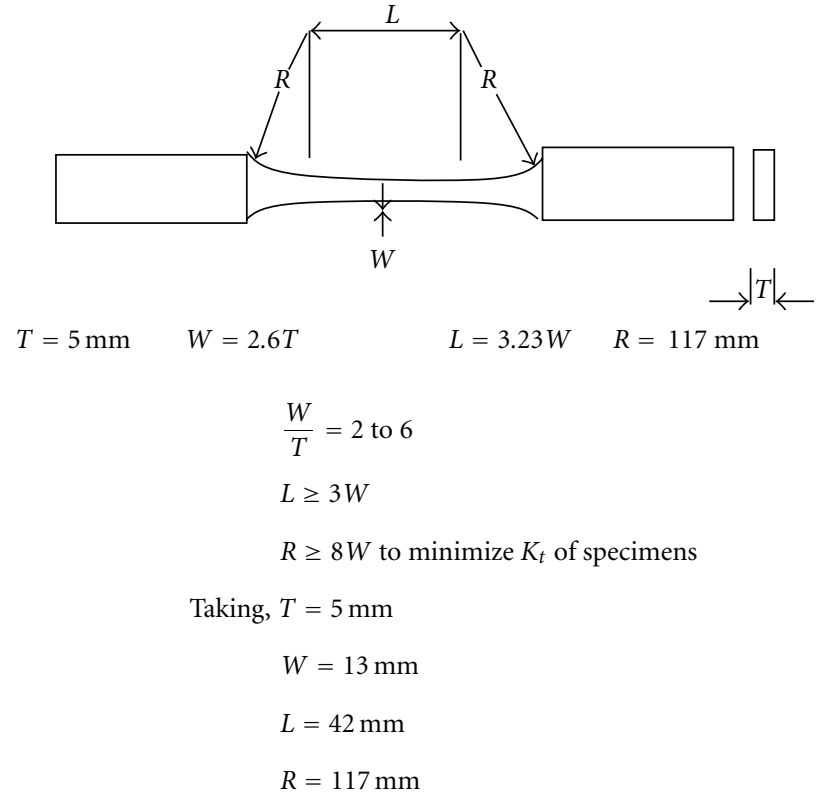

FIGURE 2: ASTM flat specimen.

3.3. Compressive Residual Stress Field. In this work, compressive residual stress field (CRSF) is determined for different shot peening conditions. Variation of CRSF with the depth of layer removed from the surface is shown in Figure 7. The observations in Table 5 are the average of three readings.

It is observed that shot peening induces the compressive residual stress on the surface up to certain depth from the surface of the sample. It is also analyzed that with increase in shot peening intensity CRSF increases. CRSF has different values at different shot peening conditions as the depth from the surface increases. It is found that CRSF is approximately the same at zero depth of layer but as the distance from the surface increases it varies for different shot peening conditions. With the increase in shot peening intensity, variation in depth of deformed layer is observed. It is also found that with shot peening there is an increase in depth of deformed layer and magnitude of compressive residual stress which directly affects the damping factor and fatigue strength of the component. It is clear from Tables 4 and 5 that damping factor improves with depth of deformed layer due to the improvement in CRSF at different shot peening intensities. 
TABLE 4: Effect of shot peening on damping factor.

\begin{tabular}{|c|c|c|c|c|c|}
\hline \multirow{2}{*}{ Depth of deformed layer ( $\mathrm{mm})$} & \multirow{2}{*}{ Almen intensity } & \multicolumn{4}{|c|}{ Damping factor } \\
\hline & & Zero depth & $0.03 \mathrm{~mm}$ depth & $0.06 \mathrm{~mm}$ depth & $0.12 \mathrm{~mm}$ depth \\
\hline 0.23 & $1 \mathrm{~A}$ & 0.09288 & 0.07829 & 0.07001 & 0.06273 \\
\hline 0.35 & $3 \mathrm{~A}$ & 0.09246 & 0.08094 & 0.07109 & 0.06472 \\
\hline 0.44 & $4.5 \mathrm{~A}$ & 0.09473 & 0.08297 & 0.07255 & 0.06735 \\
\hline 0.50 & $6 \mathrm{~A}$ & 0.09358 & 0.08307 & 0.07613 & 0.06829 \\
\hline
\end{tabular}

TABLE 5: Effect of shot peening on compressive residual stress field (CRSF).

\begin{tabular}{lccccccccccc}
\hline $\begin{array}{l}\text { Almen } \\
\text { intensity }\end{array}$ & $\begin{array}{l}\text { Depth of deformed } \\
\text { layer (mm) }\end{array}$ & $\begin{array}{l}\text { Zero } \\
\text { depth }\end{array}$ & $0.03 \mathrm{~mm}$ & $0.06 \mathrm{~mm}$ & $0.12 \mathrm{~mm}$ & $0.15 \mathrm{~mm}$ & $0.2 \mathrm{~mm}$ & $0.25 \mathrm{~mm}$ & $0.30 \mathrm{~mm}$ & $0.35 \mathrm{~mm}$ \\
\hline $1 \mathrm{~A}$ & 0.23 & -280 & -300 & -340 & -420 & -440 & -420 & -240 & -120 & -40 \\
$3 \mathrm{~A}$ & 0.35 & -280 & -340 & -360 & -500 & -520 & -460 & -260 & -140 & -40 \\
$4.5 \mathrm{~A}$ & 0.44 & -300 & -360 & -400 & -540 & -540 & -480 & -280 & -140 & -60 \\
$6 \mathrm{~A}$ & 0.50 & -280 & -360 & -440 & -560 & -580 & -500 & -280 & -180 & -60 \\
\hline
\end{tabular}

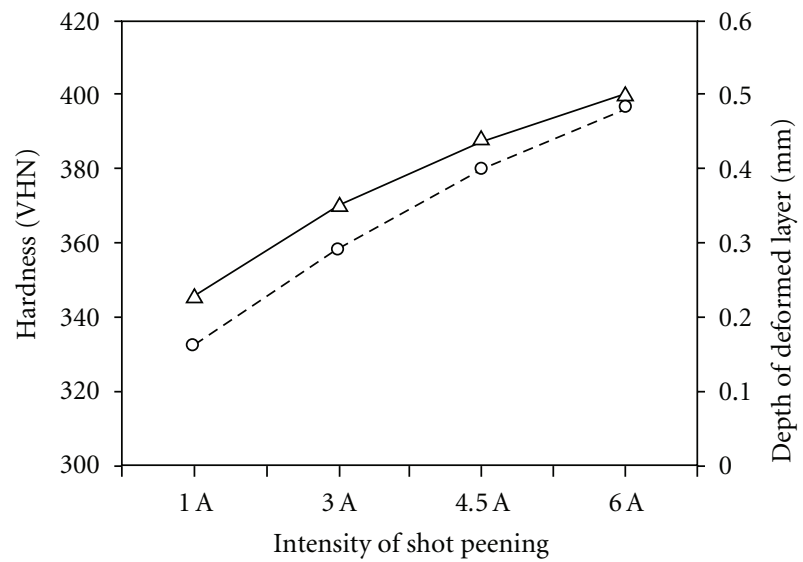

-O- Hardness (VHN)

$-\triangle$ - Depth of deformed layer $(\mathrm{mm})$

Figure 3: Variation of hardness and depth of deformed layer for different shot peening intensities.

The variation of damping factor and CRSF at different depth from the surface for Shot-peened samples at different intensity is shown in Table 6.

3.4. Damping Factor and CRSF. CRSF affects damping factor at various depth of layer removed from the surface. Damping factor and CRSF decrease with the depth of layer removed from the surface at different shot peening conditions (Table 6). A linear relationship is observed between damping factor and CRSF. The damping factor points were slightly scattered, but a straight line was best fit at different values of CRSF (Figures 8, 9, and 10). Regression analysis was used to fit the straight line in damping data at different CRSF and

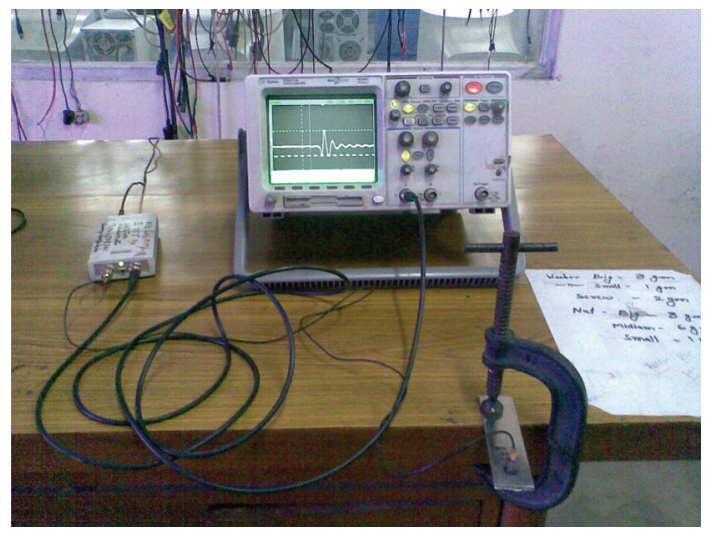

Figure 4: Experimental setup for the determination of damping factor.

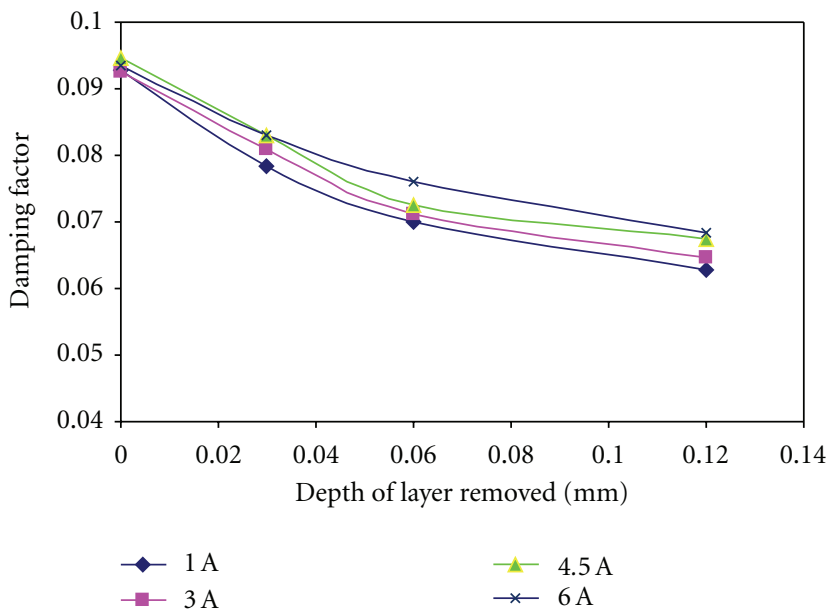

FIGURE 5: Variation of damping factor at different shot peening conditions. 
TABLE 6: Damping factor and CRSF for Shot-peened sample.

\begin{tabular}{|c|c|c|c|c|c|c|}
\hline \multirow{2}{*}{ Almen Intensity } & \multicolumn{2}{|c|}{ At $0.03 \mathrm{~mm}$} & \multicolumn{2}{|c|}{ At $0.06 \mathrm{~mm}$ depth } & \multicolumn{2}{|c|}{ At $0.12 \mathrm{~mm}$ depth } \\
\hline & Damping Factor & CRSF (MPa) & Damping Factor & CRSF (MPa) & Damping Factor & CRSF (MPa) \\
\hline $1 \mathrm{~A}$ & 0.07829 & -300 & 0.07001 & -340 & 0.06273 & -420 \\
\hline $3 \mathrm{~A}$ & 0.08094 & -340 & 0.07109 & -360 & 0.06472 & -500 \\
\hline $4.5 \mathrm{~A}$ & 0.08297 & -360 & 0.07255 & -400 & 0.06735 & -540 \\
\hline $6 \mathrm{~A}$ & 0.08307 & -360 & 0.07613 & -440 & 0.06829 & -560 \\
\hline
\end{tabular}

TABle 7: Fatigue Life of Shot-peened and base material specimen.

\begin{tabular}{|c|c|c|c|c|c|}
\hline Almen Intensity & Depth of Deformed Layer (mm) & $265 \mathrm{Mpa}$ & $240 \mathrm{Mpa}$ & $225 \mathrm{Mpa}$ & $210 \mathrm{Mpa}$ \\
\hline Base & Nil & 13629 & 73338 & 111751 & 276442 \\
\hline $1 \mathrm{~A}$ & 0.23 & 13932 & 71453 & 137487 & 492757 \\
\hline $3 \mathrm{~A}$ & 0.35 & 15149 & 97916 & 187692 & 531836 \\
\hline $6 \mathrm{~A}$ & 0.50 & 16638 & 233857 & 391427 & 861833 \\
\hline $15 \mathrm{~A}$ & 0.56 & 16610 & 213821 & 307237 & 714253 \\
\hline
\end{tabular}

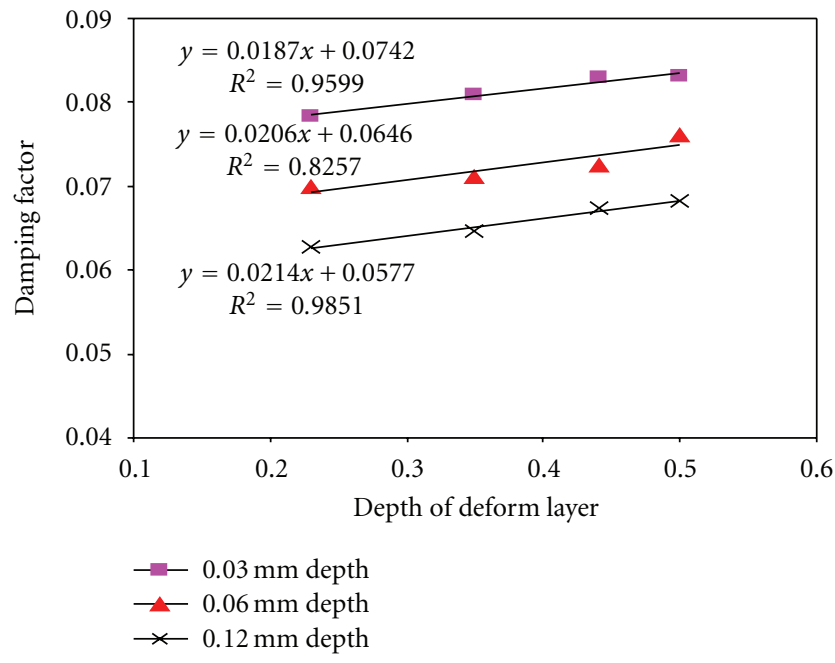

FIGURE 6: Variation of damping factor with depth of deformed layer $(\mathrm{mm})$ at different shot peening conditions.

shot peening. The expression for damping factor is expressed as

$$
\xi=m(\mathrm{CRSF})+C
$$

where $m$ is the slope of the line and $C$ is the intercept. Coefficient of determination $\left(R^{2}\right)$ varies from 0.94 to 0.99 . This value of coefficient of determination indicates that damping factor also depends on CRSF.

3.5. Fatigue Strength. Shot peening improves the fatigue strength of the components. It repairs microcracks, and, hence, the initiation of fatigue crack over the surface can be delayed by cold working of the surface with the shots $[15,16]$.

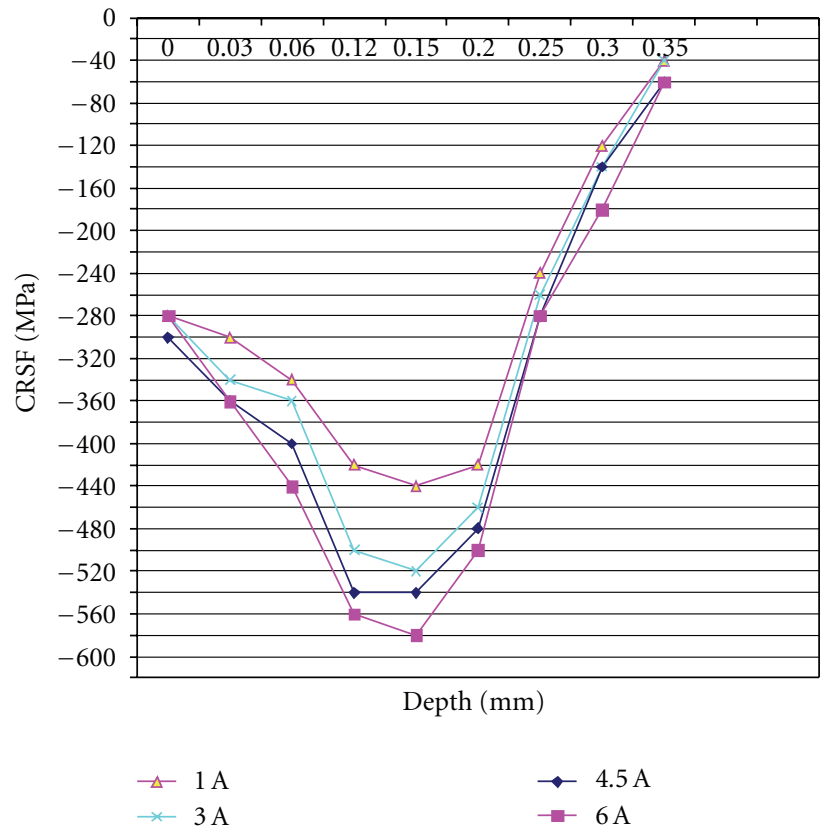

FIGURE 7: Variation of CRSF with the depth of surface for Shotpeened samples.

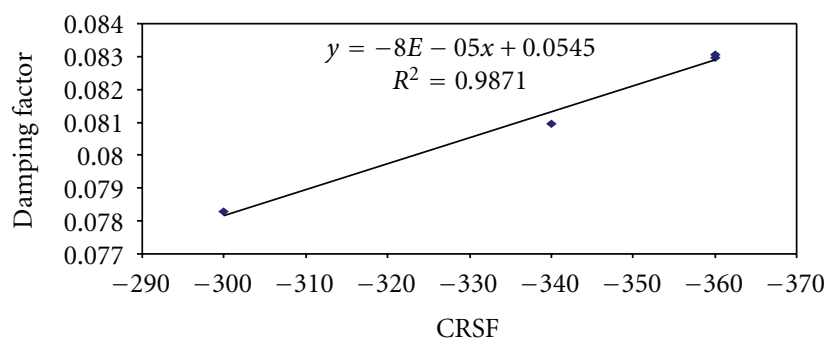

FIGURE 8: Damping factor variation with CRSF (MPa) at $0.03 \mathrm{~mm}$ from the surface of the specimen. 


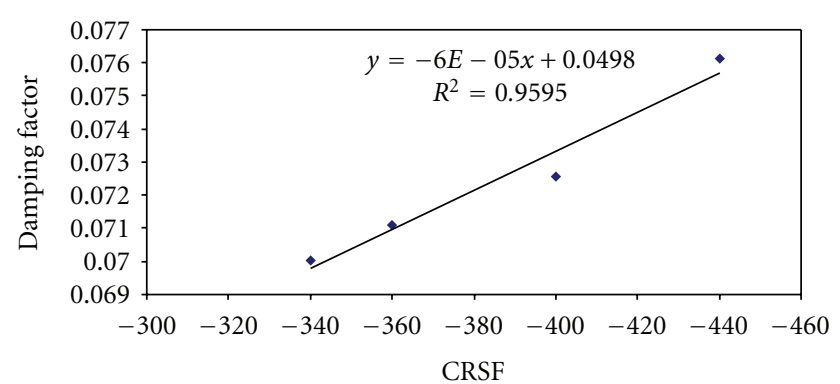

FIGURE 9: Damping Factor variation with CRSF (MPa) at $0.06 \mathrm{~mm}$ depth from the surface of the specimen.

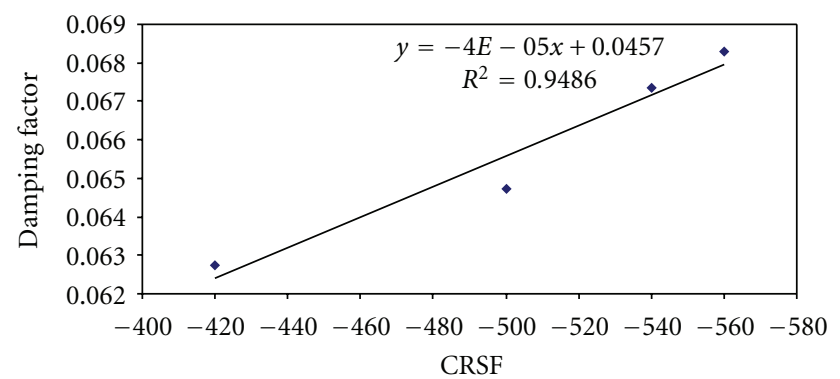

FIGURE 10: Damping Factor variation with CRSF (MPa) at $0.12 \mathrm{~mm}$ depth from the surface of the specimen.

$\mathrm{S}-\mathrm{N}$ curves for the base material and the Shot-peened specimens were determined using an axial fatigue-testing machine. The four stress levels (Table 7) were tested and more tests were conducted near the endurance limit. Fifteen specimens [17] were tested in order to plot an S/N curve. Only the average points were presented for each level (Figure 11). At different stress levels shot peening influences the fatigue strength. In relation to base material endurance limit improvement was expressive (186 MPa to $212 \mathrm{MPa}$ ). The effect of shot peening was negligible if the magnitude of the applied stress is above the endurance limit. It is important to note that there is reduction in fatigue strength at higher Almen intensities. At Almen intensity $15 \mathrm{~A}$ fatigue strength of the specimen is less as compared to the Almen intensity $6 \mathrm{~A}$ (Figure 11). This reduction in fatigue life at higher Almen intensities is due to damage of surface material, which leads to crack initiation on the surface. Hence, it is not necessary that increase in shot peening intensity will always increase fatigue strength. Also it is analysed that there is no general relationship between damping factor and fatigue life. This is due to the fact that fatigue life is less at $15 \mathrm{~A}$. However, it may be noted that damping factor increases with fatigue life, with shot peening intensity up to $6 \mathrm{~A}$.

\section{Conclusion}

The paper has accomplished the following for 304 austenitic stainless steel.

(1) Shot peening increases the hardness of 304 austenitic stainless steel. The increase in hardness was due to

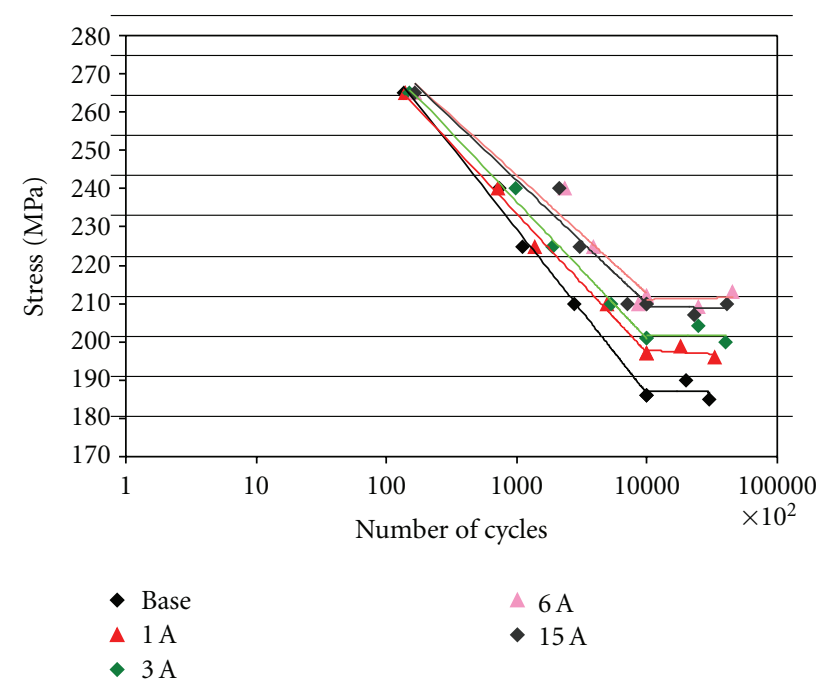

Figure 11: S/N curve for base and Shot-peened samples at different intensities.

the induction of compressive residual stress. The hardness can be controlled by controlling the different shot peening parameters.

(2) Shot peening increases the depth of deformed layer and magnitude of compressive residual stress which directly affect the damping factor and fatigue strength of the component.

(3) With the increase in thickness of layer removed from the surface, hardness of the surface increases but there is reduction in damping factor and CRSF of the specimen.

(4) Damping factor is found to be important surface characteristic which increases with shot peening. A linear relationship was found between damping factor and CRSF.

(5) It is not necessary that fatigue life increases with increasing in shot peening intensity. Overshot peening results in reduction of fatigue life.

(6) An increase in CRSF, and damping factor, is not necessary to increase the fatigue life.

\section{References}

[1] J. Talonen and H. Hänninen, "Damping properties of austenitic stainless steels containing strain-induced martensite," Metallurgical and Materials Transactions A, vol. 35, no. 8, pp. 2401-2406, 2004.

[2] R. L. Norton, Machine Design-an Integrated Approach, Pearson Education Asia, 2nd edition, 2010.

[3] P. M. George, N. Pillai, and N. Shah, "Optimization of shot peening parameters using Taguchi technique," Journal of Materials Processing Technology, vol. 153-154, no. 1-3, pp. 925-930, 2004.

[4] M. Ofsthun, "When fatigue quality enhancers do not enhance fatigue quality," International Journal of Fatigue, vol. 25, no. 911, pp. 1223-1228, 2003. 
[5] M. L. Aggarwal, V. P. Agrawal, and R. A. Khan, "A stress approach model for predictions of fatigue life by shot peening of EN45A spring steel," International Journal of Fatigue, vol. 28, no. 12, pp. 1845-1853, 2006.

[6] M. L. Aggarwal, R. A. Khan, and V. P. Agrawal, "Influence of shot peening intensity on fatigue design reliability of $65 \mathrm{Si7}$ spring steel," Indian Journal of Engineering and Materials Sciences, vol. 12, no. 6, pp. 515-520, 2005.

[7] M. L. Aggarwal, "Shot peened high nitrogen austenitic stainless steel: An alternate to Ni rich austenitic steel for medical applications," in Proceedings of the International conference on materials for advanced technologies, vol. 2007, p. 31, Singapore, 2007.

[8] L. Singh, R. A. Khan, and M. L. Aggarwal, "Influence of residual stress on fatigue design of AISI 304 stainless steel," Journal of Engineering Research. In press.

[9] J. L. Meriam and L. G. Kraige, "Engineering mechanics," in Dynamics, vol. 2, pp. 593-600, John Wiley \& Sons, Singapore, 5th edition, 2002.

[10] E. D. George, Mechanical Metallurgy, McGraw-Hill, London, UK, 3rd edition, 1961.

[11] M. Moriyama, T. Nagano, N. Kawagoishi, S. Takaki, and E. Nagashima, "Effect of shot peening on fatigue strength of $18 \% \mathrm{Ni}$ maraging steel," JSME International Journal. Series A, vol. 44, no. 2, pp. 301-308, 2001.

[12] H. Soyama and D. Macodiyo, "Improvement of fatigue strength on stainless steel by cavitating jet in air," in Proceedings of the 5th International Symposium on Cavitation (CAV '03), pp. 1-4, Osaka, Japan, 2003.

[13] G. H. Farrahi and H. Ghadbeigi, "An investigation into the effect of various surface treatments on fatigue life of a tool steel," Journal of Materials Processing Technology, vol. 174, no. 1-3, pp. 318-324, 2006.

[14] R. B. Waterhouse, B. Noble, and G. Leadbeater, "The effect of shot-peening on the fretting-fatigue strength of an agehardened aluminium alloy (2014A) and an austenitic stainless steel (En 58A)," Journal of Mechanical Working Technology, vol. 8, no. 2-3, pp. 147-153, 1983.

[15] M. C. Sharma, "Shot Peening and Blasting," in Proceedings of the International of the international Conference on Shot Peening and Sand Blasting, pp. 190-195, 2001.

[16] J. P. Strizak, H. Tian, P. K. Liaw, and L. K. Mansur, "Fatigue properties of type 316LN stainless steel in air and mercury," Journal of Nuclear Materials, vol. 343, no. 1-3, pp. 134-144, 2005.

[17] SAE Annual Book of ASTM Standards, part 10, 1977. 

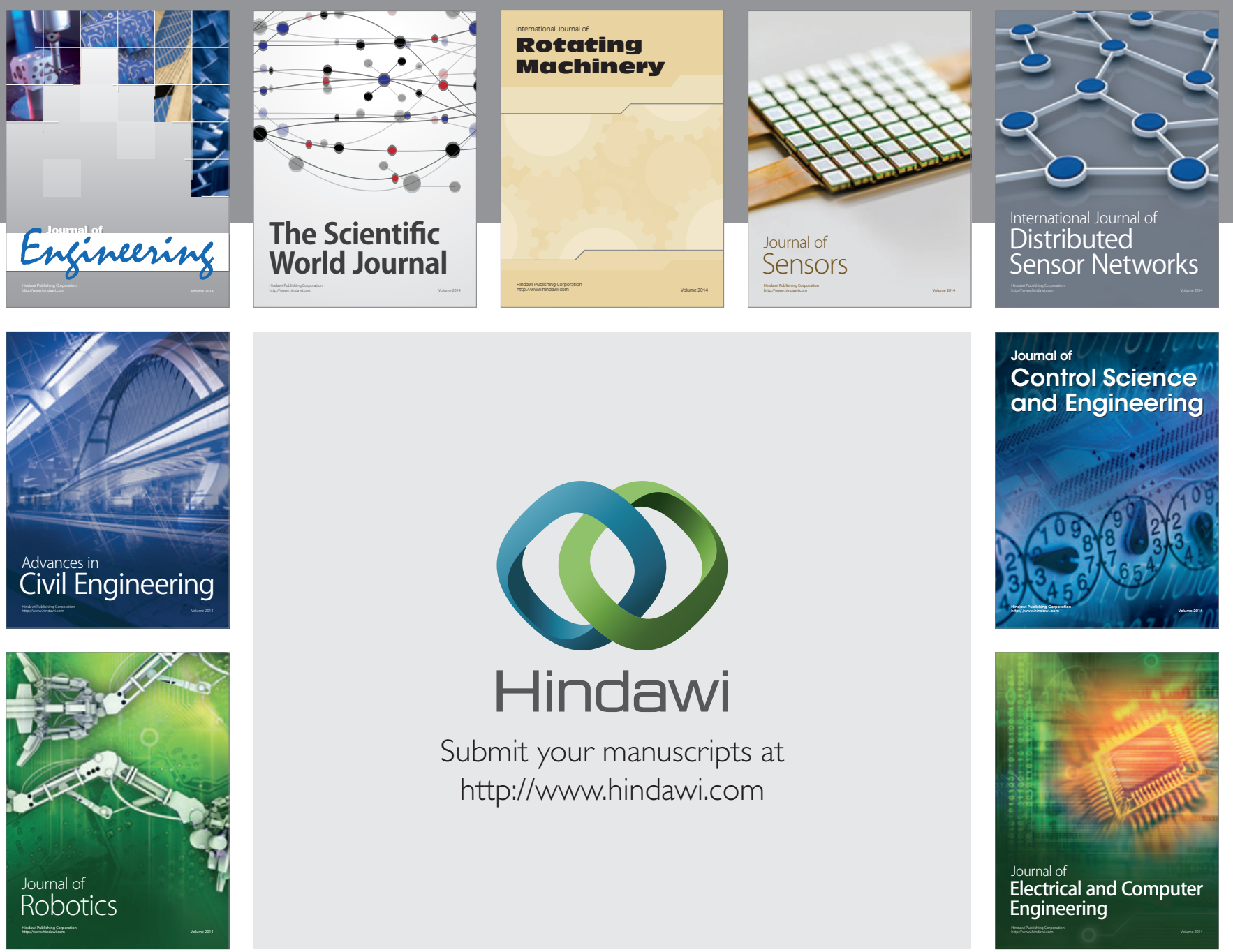

Submit your manuscripts at

http://www.hindawi.com
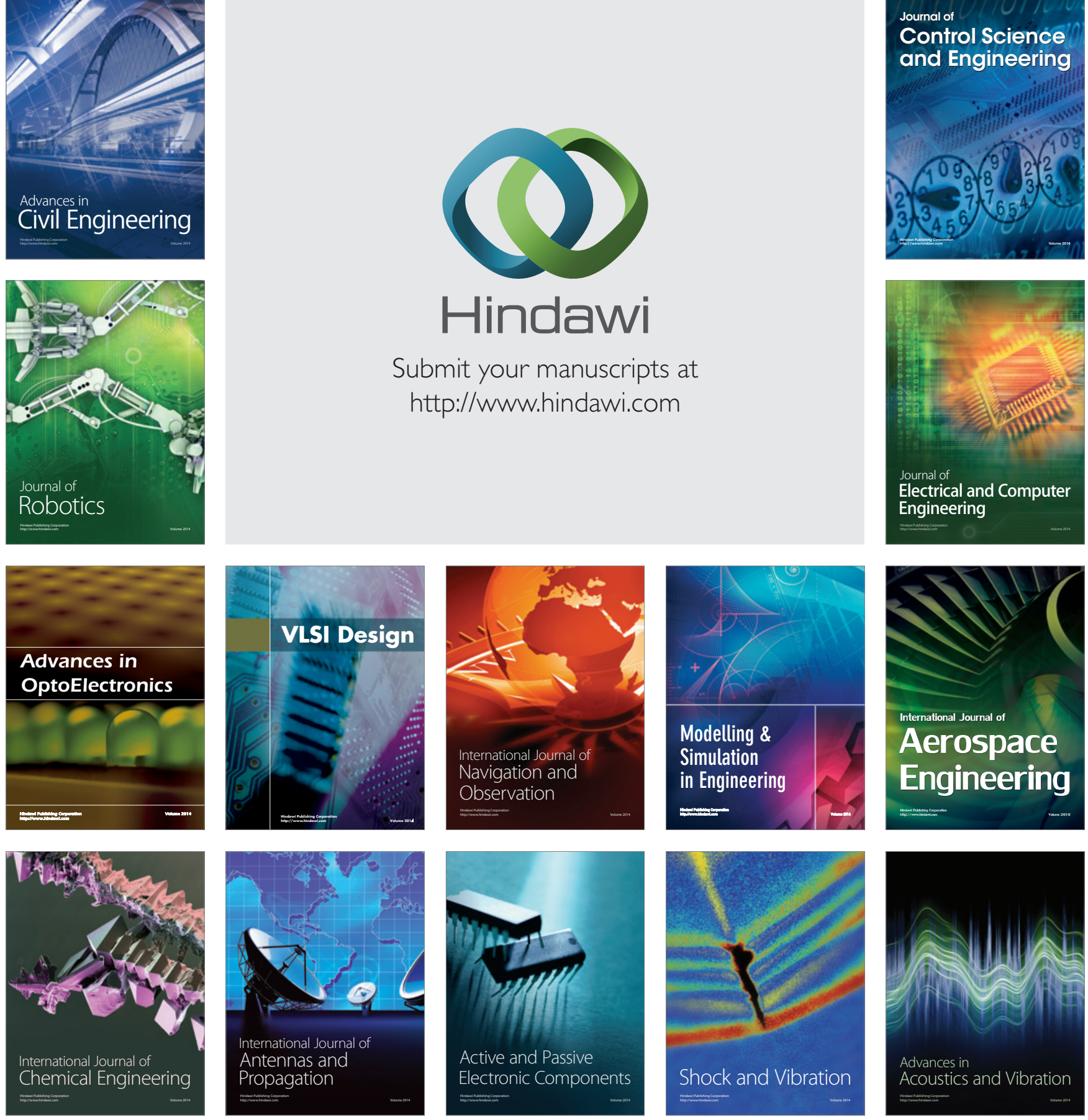